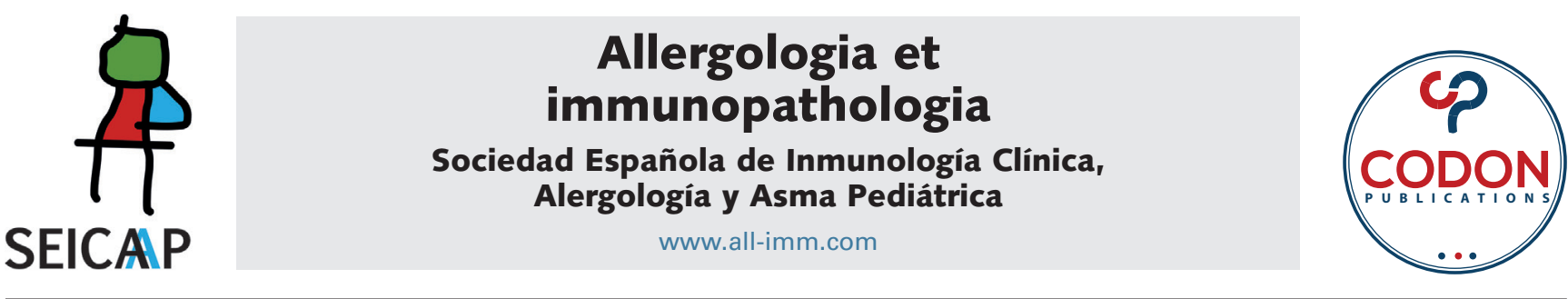

\title{
Prevalence of allergic disorders and risk factors associated with food allergy in Turkish preschoolers
}

\author{
Ayşen Genç Aksoya, Perran Borana, Elif Karakoc-Aydiner ${ }^{\mathrm{b} *}$, Gulbin Gokcay ${ }^{\mathrm{c}, \mathrm{d}}$, Zeynep Ulker \\ Tamay $^{\mathrm{d}}$, Esra Deveciogluc ${ }^{\mathrm{c}}$, Safa Baris ${ }^{\mathrm{b}}$, Ahmet Ozen ${ }^{\mathrm{b}}$
}

\author{
aschool of Medicine, Division of Social Pediatrics, Marmara University, Istanbul, Turkey \\ ${ }^{b}$ School of Medicine, Division of Pediatric Allergy and Immunology, Marmara University, Istanbul, Turkey \\ 'Department of Social Pediatrics, Institute of Child Health, Istanbul University, Istanbul, Turkey \\ ${ }^{d}$ Division of Social Pediatrics, School of Medicine, Istanbul University, Istanbul, Turkey \\ eIstanbul Medical Faculty, Division of Pediatric Allergy and Immunology, Istanbul University, Istanbul, Turkey
}

Received 12 April 2020; Accepted 3 October 2020

Available online 2 January 2021

\section{KEYWORDS \\ food allergy; \\ egg white; \\ infant; \\ breastfeeding, risk \\ factors}

\begin{abstract}
Background: The prevalence of allergic disorders is on the rise, affecting about $10 \%$ of the population. In this retrospective cohort, we investigated prevalence of allergic disorders, associated risk factors, and the outcome of food allergies.

Material and methods: We analyzed data from birth cohorts of two university hospitals' wellchild outpatient clinics. Factors related to onset and type of allergic diseases were assessed from demographic, socioeconomic, and clinical data.

Results: Analyses were performed on $949(431 \mathrm{~F} / 518 \mathrm{M})$ infants at a mean current age of $28 \pm 6$ months. Any allergic disease was established among 177 cases (22\%); atopic dermatitis in 123 (12.8\%), respiratory allergies in 55 (5.7\%), and food allergy in 41 (4.3\%). The risk for allergic disorders was found to be significantly increased for male gender (OR: 2.31, 95\% Cl; 1.54-3.46), and positive parental atopy (OR: 1.94, 95\% Cl; 1.31-2.86). The risk of food allergies was significantly higher in the male gender (OR: 2.47, 95\% Cl; 1.21-5.02), who consumed egg-white between 6 and 12 months (OR: $2.34,95 \% \mathrm{Cl} ; 1.22-4.48$ ), and who were formula-fed before 6 months (OR: 2.16, $95 \% \mathrm{Cl} ; 1.14-4.10)$. We found no significant association between the rate of food allergy outgrowth or food induced-anaphylaxis with regards to the timing of introducing egg-white into the diet. Conclusions: Although the introduction of egg-white into infant diet at 6-12 months of life appeared as an independent risk for any food allergy, none of the patients developed anaphylaxis. Age at symptom onset and outgrowing food allergy were similar compared to those introduced egg-white after 12 months. We recommend promoting exclusive breastfeeding during the first 6 months of life, and avoidance of prolonged restrictive diets for children with food allergy. (c) 2021 Codon Publications. Published by Codon Publications.
\end{abstract}

*Corresponding author: Prof. Dr. Elif Karakoc-Aydiner. Division of Pediatric Allergy-Immunology, Marmara University, Istanbul 34890, Turkey. Email address: elif_karakoc@hotmail.com 


\section{Introduction}

Allergic disorders affect all ages and have serious health consequences. Food allergies, in particular hen's egg and cow's milk allergy are the most common food allergies in early childhood, with an estimated prevalence of $1-10 \%$ around the globe. ${ }^{1,2}$

Few studies have investigated the prevalence of allergy in Turkey. ${ }^{3-5}$ Based on the study conducted in Southern Turkey, the overall prevalence of confirmed food allergy in the first year of life was estimated to be $2.4 \%$, and the prevalence of cow's milk allergy was $1.45 \% .^{3}$ Previously, it had been suggested that exposure to the food allergen early in life was important in food allergy development. Thus, allergen avoidance or delaying the introduction of foods into the infant's diet has been a primary prevention strategy for allergy. On the contrary, current evidence shows no benefit of such recommendations, as revealed by the high food allergy rates among countries that adopted these recommendations into practice. ${ }^{6}$ In 2008, the American Academy of Pediatrics Committee on Nutrition and Allergy Immunology suggested that there are insufficient data to document a protective effect of any dietary intervention beyond 4 to 6 months of age for the development of atopic diseases. ${ }^{7}$ Furthermore, it is suggested that tolerance to food allergens is driven by regular, early exposure to antigens during a critical early window period, which is between 4 and 6 months of life. Alongside these observations, continued breastfeeding during this period promotes tolerance and protects from allergy. ${ }^{8}$ From the view of the European Academy of Allergy and Clinical Immunology, the evidence does not support avoidance as an allergy prevention strategy. They state that current evidence does not justify any recommendations about either delaying or encouraging exposure to potentially allergenic foods after 4 months for exclusively breastfed infants. ${ }^{6}$ Taken together, there is an unmet need with regards to the potential benefits, and risks, of introducing various foods in complementary feeding of young infants.

In this study, we aimed to assess the prevalence of allergic disorders and associated risk factors in a welldefined Turkish birth cohort who were followed up until 3 years of age. Additionally, the outcome of food allergies was evaluated.

\section{Materials and methods}

In this retrospective birth cohort, we analyzed data from two birth cohorts of two university hospitals' well-child outpatient clinics located in Istanbul. Data collection for the study was carried out between April 2015 and July 2015. The data obtained were those of newborns born at the maternity clinics of the university hospitals between December 2011 and December 2012, who were followed up at the well-child outpatient clinics. Mothers who gave birth at the university hospital's maternity clinics receive a pamphlet with information regarding how to make an appointment at the well-child outpatient clinics. Each healthy newborn is scheduled for a first appointment at 2-4 weeks of age and is then followed up every monthly for the first 6 months, at 3-monthly intervals until 18 months of age, and then every 6 months up to 5 years of age. Physical examinations, growth and developmental surveillance, immunizations, and age-appropriate anticipatory guidance are provided during these visits. Birth numbers vary between 1500 and 2500 per year, and in general one out of three mother-infant dyads started an outpatient follow-up. Eligibility criteria included regular well-child visits during the observation period. Collected data from the personalized medical files included demographics, family socioeconomic status (SES), mode of delivery, parental atopy or smoking, breastfeeding history, formula feeding, age at introduction of egg white and cow's milk into complementary feeding, presenting symptoms and laboratory data of allergic diseases including atopic dermatitis, respiratory allergies, and food allergy. Exclusion criteria included premature birth and infants who develop chronic diseases. Diagnoses of respiratory allergies, atopic dermatitis, and food allergy were based on a consensus decision between pediatric allergy and pediatrics specialists in accordance with the guidelines, $6,9,10$ and food allergy was confirmed in the presence of typical clinical symptoms and positive oral provocation test. ${ }^{6}$ Patients with food allergy were categorized into lgE mediated, non-IgE mediated, or mixed type. In addition, allergic sensitization was defined as serum-specific IgE $\geq 0.35 \mathrm{ku} / \mathrm{L}$ and/or wheal diameter more than $3 \mathrm{~mm}$ in a skin prick testing with egg, and cow's milk, soy, wheat, nuts, peanut, fish allergens. Oral tolerance is defined as a state of local and systemic immune unresponsiveness induced by oral administration of innocuous allergens. ${ }^{6}$

Continuous variables were investigated for normal distribution using visual and analytical methods. Descriptive analyses were presented using means and standard deviation for normally distributed variables and medians for the non-normally distributed or ordinal variables. Between-group comparisons were made by Wilcoxon rank-sum non-parametric tests for the non-normally distributed continuous variables. The univariate analyses to identify variables associated with patient outcomes were investigated using Chi-square tests. Delivery type, gender, socioeconomic status, birth order, parental atopy and smoking status, being formula fed in the first 6 months of life, exclusive breastfeeding, and complementary food introduction at 4-6 months of life, egg white, whole cow's milk consumption or both at 6-12 months of life, maternal age, and education level were considered as potential confounders. For the multivariate analysis, the possible factors identified with univariate analyses were further entered into the logistic regression analysis to determine independent predictors of allergy. Any allergic disorder and food allergy are considered separately as dependent factors and binary logistic regression analysis is applied using the enter approach. Statistical analyses were performed using the IBM SPSS Statistics for Windows, Version 20.0. (IBM Corp.; Armonk, NY, USA). The study was approved by the Research Ethics Committee of the Faculty of Medicine at the University of Marmara with the number 09.2014.0308.

\section{Results}

\section{Study design and population}

A total of 1053 eligible patient files out of 1767 births were screened and 104 of them were excluded due to 
prematurity. The final analyses were performed on 949 $(431 \mathrm{~F} / 518 \mathrm{M})$ infants at a median age of $28 \pm 6$ months. Baseline demographic characteristics of the study group are presented in Table 1. Delivery via caesarian section was $60.4 \%$ ( $n=573$ ). Exclusively breastfed babies in the first 6 months of life comprised $38 \%$ of the cohort $(\mathrm{n}=$ 361). Formula ever fed babies in the first 6 months of life was $40 \%(n=380)$. The socioeconomic status of the entire cohort was overall high with $67.7 \%$ being in the high SES group and $32.3 \%$ in the moderate.

\section{Prevalence of allergic disorders and risk factors}

A total of 177 (22\%) children had allergies. The individual prevalence of allergic disorders is presented in Figure 1. Food allergic patients $(n=41)$ comprised $4.3 \%$ of the cohort, respiratory allergies were seen at a rate of $5.7 \%$ $(n=55)$, and atopic dermatitis being the most commonly diagnosed allergic disorder had a prevalence rate of $12.8 \%$ $(n=123)$. Of the children with a food allergy, $19(46.3 \%)$ were found to be allergic to egg white; 14 (34.1\%) to cow's milk; and eight (19.5\%) were allergic to both allergens. Cow's milk allergy rate was found to be $2.3 \%$ and egg white as $2.7 \%$. When evaluating the type of allergy, 12 patients had IgE-mediated (29.2\%) and 29 (70.7\%) had mixed or nonIgE mediated allergies.

The risk for allergic disorders was found to be significantly increased for the male gender (OR: $2.31,95 \% \mathrm{Cl}$; 1.54-3.46) and in the presence of parental atopy (OR: 1.94, $95 \% \mathrm{Cl} ; 1.31-2.86)$. Food allergy was significantly higher in the male gender (OR: 2.47, 95\% Cl; 1.21-5.02), in those who consumed egg white between 6 and 12 months (OR: 2.34, 95\% Cl; 1.22-4.48) and who were formula fed in the first 6 months of life (OR: 2.16, 95\% Cl; 1.14-4.10) (Table 2). Symptoms related to food allergy with respect to the timing of introducing egg white, cow's milk, or both, are presented in Table 3.

Table 1 Demographics and feeding practices of the study population.

\begin{tabular}{lc}
\hline & $\begin{array}{c}\text { Study } \\
\text { population } \\
\mathrm{n}=949\end{array}$ \\
\hline Age (months) & $28 \pm 6$ \\
Gender (M/F\%) & $518(54.6 \%) /$ \\
& $431(45.4 \%)$ \\
Mode of delivery (C/S / NSD) & $573(62.6 \% /$ \\
& $342(37.4 \%)$ \\
SES (\%) & $303(32.2 \%)$ \\
$\quad$ Moderate & $636(67.7 \%)$ \\
High & $637(67.8 \%)$ \\
Exclusive breastfeeding for 4 months $\mathrm{n}(\%)$ & $361(38.4 \%)$ \\
Exclusive breastfeeding for 6 months $\mathrm{n}(\%)$ & $380(40 \%)$ \\
Formula feeding during the first 6 months & \\
$\quad \mathrm{n}$ (\%) & \\
\hline
\end{tabular}

NSD: Normal spontaneous delivery; C/S: Cesarean section; SES: Socioeconomic status.

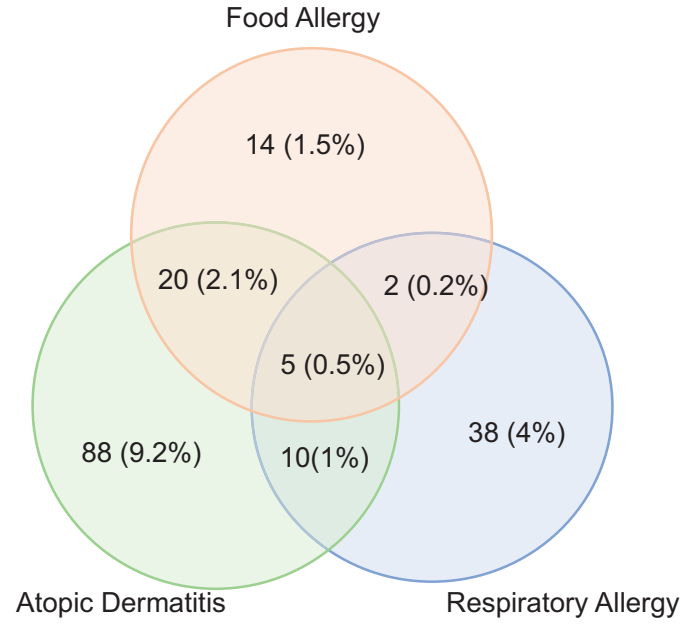

Figure 1 Prevalence of allergic disorders by subgroups of atopic dermatitis, respiratory and food allergies.

\section{Outcome}

The mean age of symptom onset and age of tolerance for food allergies was similar between infants who consumed egg white at 6 to 12 months of life $(n=418)$ versus beyond 12 months $(n=531)(6.5 \pm 3.4$ vs. $6.0 \pm 3.83$ months, $p=0.65$ and $21.6 \pm 9.4$ vs. $20.1 \pm 6.7$ months, $p=0.59$; respectively). Around $92 \%$ of those who consumed egg white between 6 and 12 months and $87 \%$ of those who consumed beyond 12 months outgrew their food allergies at the end of a mean 28 months of follow-up duration. Anaphylaxis developed in only one child who did not consume egg white during the first year of life. Notably, any anaphylaxis was not observed among children who had egg white introduced at 6 to 12 months of age during the observation period.

\section{Discussion}

This study including two birth cohorts of 949 infants who were followed up for a mean duration of 28 months; the prevalence of food allergy, respiratory allergies, and atopic dermatitis was 4.3 (cow's milk 2.3\% and egg white $2.7 \%$ ), 5.8 and $12.9 \%$, respectively. We observed a higher prevalence of allergic disorders including food allergy in Turkish children ${ }^{3,11}$ compared to Europe, but our results are in line with other countries' reported values.,12 Our observations in the current study are in accordance with reports by Rona et al., ${ }^{12}$ who reported the prevalence of food allergy as 0.2 to $7 \%$ for the egg, and 3 to $35 \%$ for any food. In a trial by Perkin et al.,13 1303 exclusively breastfed infants were randomly assigned to the early introduction of six allergenic foods (peanut, cooked egg, cow's milk, sesame, whitefish, and wheat) or to the current standard practice. Food allergy developed in $7.1 \%$ of the participants in the standard-introduction (after 6 months) group and in $5.6 \%$ of those in the early introduction (after 4 months) group.

The infants included in the study were enrolled from birth cohorts followed up in well-child outpatient clinics of two universities, which are tertiary centers. Thereby, there 
Table 2 Risk factors associated with allergic disorders and food allergy.

\begin{tabular}{|c|c|c|c|}
\hline Risk factors for & $\begin{array}{c}\text { Univariate binary regression analysis } \\
\text { unadjusted OR }(95 \% \mathrm{Cl})\end{array}$ & $\begin{array}{l}\text { Binary logistic regression analysis } \\
\text { (enter method) adjusted OR }(95 \% \mathrm{Cl})\end{array}$ & $\mathrm{p}$ \\
\hline \multicolumn{4}{|l|}{ Allergic disorders } \\
\hline Gender (male vs. female) & $1.92(1.36-2.70)$ & $2.31(1.54-3.46)$ & $<0.001$ \\
\hline Parental atopy & $1.96(1.33-2.89)$ & $1.94(1.31-2.86)$ & 0.001 \\
\hline \multicolumn{4}{|l|}{ Food allergy } \\
\hline Gender (male vs. female) & $2.34(1.16-4.74)$ & $2.47(1.21-5.02)$ & 0.012 \\
\hline $\begin{array}{l}\text { Egg white consumption } \\
\text { between } 6 \text { and } 12 \text { months }\end{array}$ & $2.04(1.08-3.88)$ & $2.34(1.22-4.48)$ & 0.010 \\
\hline $\begin{array}{l}\text { Formula feeding in the first } \\
6 \text { months of life }\end{array}$ & $1.97(1.05-3.70)$ & $2.16(1.14-4.10)$ & 0.018 \\
\hline
\end{tabular}

OR: odds ratio, p: statistical significance.

Table 3 Symptoms associated with food allergy with respect to the timing of the introduction of egg white into the diet.

\begin{tabular}{|c|c|c|c|c|c|c|}
\hline \multirow{2}{*}{$\begin{array}{l}\text { Age at egg white introduction } \\
\text { Food allergy }\end{array}$} & \multicolumn{3}{|c|}{$6-12$ months $n=25$} & \multicolumn{3}{|c|}{$>12$ months $n=16$} \\
\hline & Egg & Cow's milk & Egg-Cow's milk & Egg & Cow's milk & Egg-Cow's milk \\
\hline \multicolumn{7}{|l|}{ Symptoms } \\
\hline Urticaria & 7 & 2 & & 2 & 2 & \\
\hline Atopic dermatitis & 6 & & 1 & 1 & 4 & 2 \\
\hline Angioedema & 1 & & & & 1 & \\
\hline Gut symptoms & 2 & 3 & 3 & & 1 & 2 \\
\hline Anaphylaxis & & & & & 1 & \\
\hline
\end{tabular}

might have been a bias towards timely diagnoses of allergic disorders where an allergy evaluation is fairly accessible. Nonetheless, despite being verified by a physician, not all patients underwent the gold standard diagnostic food challenge. Previous reports indicate higher allergy prevalence among families with high socioeconomic status. In our cohort, approximately $67 \%$ of the parents were from high socioeconomic status, potentially contributing to our finding of high allergy rates. We found two factors: introduction of egg white into the diet of infants after 6 months of age and formula feeding during the first 6 months of life, to be associated with heightened risk for food allergy. Additionally, the male gender was found to be a risk factor for both developing an allergic disorder and food allergy, which is in line with the previous studies. Currently, there is an ongoing debate on the optimal timing of solid food introduction to infants as a potentially modifiable risk factor for food allergy. In a recent meta-analysis, Burgess et al. ${ }^{14}$ demonstrated that egg consumption during 4 to 6 months and peanut consumption during 4 to 11 months were found to be protective from relevant allergies in randomized controlled trials. Koplin et al. ${ }^{15}$ found that compared with the introduction at 4-6 months, introducing egg after 10 months of age was associated with a higher risk for egg allergy. They concluded that the introduction of the cooked egg at 4-6 months of age might protect against egg allergy. Moreover, Nwaru et al. ${ }^{1}$ found that the late introduction of eggs $(>10.5$ months) was significantly associated with sensitization to food allergens. The Enquiring About Tolerance (EAT) study, included 1303 breastfed 3-month-old infants from the general population. ${ }^{13}$ The study's results confirmed a non-significant 20\% lower relative risk of food allergy (peanuts, egg, cow's milk, sesame, white fish, and wheat) in the early introduction group (5.6\%) than in the standard introduction group $(7.1 \%)$ by the time the children were 3 years of age $(p=0.32)$. However, when the analysis was adjusted for adherence to the early introduction group, there was a statistically significant reduction in food allergy in the early introduction group $(2.4 \%$ vs. $6.4 \% ; p=0.03)$, suggesting the introduction of sufficient amounts of allergenic foods into the infant diet at 3-6 months with continued breastfeeding may be effective in the prevention of food allergy. On the other hand, the Hen's Egg Allergy Prevention (HEAP) study found no evidence that consumption of hen's egg starting at 4-6 months of age prevents hen's egg sensitization or allergy in the general population. ${ }^{16}$ They also observed a very high prevalence of hen's egg sensitization (5.7\%) at 4-6 months of age before the intervention and found no evidence that consumption of hen's egg starting at 4-6 months of age prevented hen's egg sensitization or allergy. ${ }^{16}$ In contrast with previous studies, ${ }^{1,14,15}$ our study showed that egg allergy was significantly higher in those who were introduced to egg white between 6 and 12 months of age as compared to after 12 months of age. However, the time of outgrowing allergy was similar in both groups, with a median age of 21 versus 20 months, respectively. In the literature, it is estimated that approximately $50 \%$ of children with an egg allergy will outgrow their sensitivities within 36 months 
following diagnosis. ${ }^{17}$ Likewise, the outgrowth of allergy is estimated to occur by 1 year in up to $50 \%$ of subjects and before 3 years among $85 \% .{ }^{5}$ In our cohort, 92 and $87 \%$ of the infants who consumed egg white at 6-12 months of life and beyond 12 months, respectively, outgrew their allergies by 28 months, which is in line with the previous reports ( 85 to $90 \%$ in 3 years).

An estimated 10 to $15 \%$ of the population report symptoms of food allergy throughout their lifespan, although the prevalence of Ig-E mediated food allergies is reported to be lower at approximately 2 to $5 \%$ and 6 to $8 \%$ of young children.12,18,19 Among our cohort, only one-third of the patients were identified to have IgE-mediated food allergy based on available data.

The general practice for allergic children is strict allergen avoidance once a diagnosis is made, to avoid anaphylaxis which may occur any time. ${ }^{6}$ However, there are drawbacks to strict elimination diets, including growth retardation, nutritional deficiencies, and impaired quality of life for both the parents and the children. ${ }^{20-22}$ Ongoing studies evaluate the role of exposing allergic children to minute amounts of offending food via processing, termed oral immune tolerance induction, to overcome some of the detrimental effects of strict elimination diets. Despite the fact that we observed an increased prevalence of egg allergy among infants who were introduced to egg white at 6-12 months compared to the delayed introduction, these allergies were not associated with anaphylaxis. Moreover, both groups had similar figures when age at symptom onset and age at outgrowth of food allergies. Combined, we cannot draw unequivocal conclusions as to the best timing of introducing egg-white into infant diet. However, we believe our data would not favor a delayed introduction as a great majority of children were able to tolerate an early introduced regimen (between 6 and 12 months). Our findings also support the role of formula feeding during the first 6 months of life on an increased risk of food allergy.

There are certain limitations to the study. Firstly, the number of children diagnosed with food allergy was small, decreasing the statistical power. Another limitation is the retrospective nature of data collection, as we cannot quantify the amount of egg-protein consumed. In addition, this study is an observational retrospective birth cohort study and cannot determine causality, only associations. Reverse causality (egg allergy prior to the introduction of egg white preventing the infant's acceptance of complementary foods), selection bias (inclusion of infants who had parental atopy history), and/or uncontrolled confounding factors might explain these results. Although the double-blind placebo-controlled food challenge is considered as the gold standard in the diagnosis of food allergy, it was not available for all patients. ${ }^{7}$ Overall, this might be the most plausible explanation for the observed higher rate of egg allergy among infants who were introduced to egg white at 6-12 months compared to delayed introduction. However, in a recent survey, it was shown that only $10 \%$ of the world allergy organization member countries had food allergy prevalence data based on oral food challenges, and experts in this era consider the use of an open challenge to be appropriate for infants. ${ }^{22}$

In conclusion, physician-verified diagnoses of allergic disorders in our cohort are higher than reported ones, and based on our findings, we recommend promoting exclusive breastfeeding during the first 6 months of life, and avoidance of prolonged restrictive diets for children with food allergy.

\section{References}

1. Nwaru BI, Hickstein L, Panesar SS, Roberts G, Muraro A, Sheikh A, et al. Prevalence of common food allergies in Europe: a systematic review and meta-analysis. Allergy. 2014;69(8): 992-1007. https://doi.org/10.1111/all.12423

2. Prescott SL, Pawankar R, Allen KJ, Campbell DE, Sinn JKH, Fiocchi A, et al. A global survey of changing patterns of food allergy burden in children. World Allergy Organ J. 2013;6:21. https://doi.org/10.1186/1939-4551-6-21

3. Doğruel D, Bingöl G, Altıntaș DU, Yılmaz M, Kendirli SG. Clinical features of food allergy during the first year of life: The ADAPAR Birth Cohort Study. Int Arch Allergy Immunol. 2016;169:171-180. https://doi.org/10.1159/000443831; https:// doi.org/10.1159/000444639

4. Sekerel BE, Seyhun O. Expert panel on practice patterns in the management of cow's milk protein allergy and associated economic burden of disease on health service in Turkey. J Med Econ. 2017;20(9):923-930. https://doi.org/10.1080/13696 998.2017.1342171

5. Kansu A, Yüce A, Dalgıç B, Şekerel BE, Çullu-Çokuğraș F, Çokuğraș $\mathrm{H}$. Consensus statement on diagnosis, treatment and follow up of cow's milk allergy among infants and children in Turkey. Turkish J Ped. 2016;58:1-11. https://doi.org/10.24953/ turkjped.2016.01.001

6. Muraro A, Werfel T, Hoffmann-Sommergruber K, Roberts G, Beyer K, Bindslev-Jensen C, et al. EAACl Food Allergy and Anaphylaxis Guidelines Group. EAACl food allergy and anaphylaxis guidelines: diagnosis and management of food allergy. Allergy. 2014;69(8):1008-1025. https://doi.org/10.1111/ all.12441; https://doi.org/10.1111/all.12429

7. Greer FR, Sicherer SH, Burks AW; Committee on Nutrition; Section on Allergy and Immunology. The effects of early nutritional interventions on the development of atopic disease in infants and children: the role of maternal dietary restriction, breastfeeding, hydrolyzed formulas, and timing of introduction of allergenic complementary foods. Pediatrics. 2019;143(4):e20190281. https://doi.org/10.1542/ peds.2019-0281

8. Prescott SL, Smith P, Tang M, Palmer DJ, Sinn J, Huntley SJ, et al. The importance of early complementary feeding in the development of oral tolerance: concerns and controversies. Pediatr Allergy Immunol. 2008;19:375-380. https://doi. org/10.1111/j.1399-3038.2008.00718.x

9. Global Initiative for Asthma. Global strategy for asthma management and prevention, 2019. Available from: www.ginasthma.org [accessed September 2, 2019].

10. Eichenfield LF, Tom WL, Chamlin SL, Feldman SR, Hanifin JM, Simpson EL, et al. Guidelines of care for the management of atopic dermatitis: section 1. Diagnosis and assessment of atopic dermatitis. J Am Acad Dermatol. 2014;70(2):338-351. https://doi.org/10.1016/j.jaad.2013.10.010

11. Doğruel D, Bingöl G, Altıntaș DU, Yılmaz M, Kendirli SG. Prevalence of and risk factors for atopic dermatitis: a birth cohort study in infants in southeast Turkey. Allergol Immunopathol (Madr). 2016;44(3):214-220. https://doi. org/10.1016/j.aller.2015.07.002

12. Rona RJ, Keil T, Summers C, Gislason D, Zuidmeer L, Sodergren $\mathrm{E}$, et al. The prevalence of food allergy: a meta analysis. J Allergy Clin Immunol. 2007;120:638-646. https:// doi.org/10.1016/j.jaci.2007.05.026 
13. Perkin MR, Logan K, Tseng A, Raji B, Ayis S, Peacock J, et al. Randomized trial of introduction of allergenic foods in breastfed infants. N Engl J Med. 2016;374:1733-1743. https://doi. org/10.1056/NEJMoa1514210

14. Burgess JA, Dharmage SC, Allen K, Koplin J, Garcia-Larsen V, Boyle R, et al. Age at introduction to complementary solid food and food allergy and sensitization: a systematic review and meta-analysis. Clin Exp Allergy. 2019;49(6):754-769. https://doi.org/10.1111/cea.13383

15. Koplin JJ, Osborne NJ, Wake M, Martin PE, Gurrin LC, Robinson MN, et al. Can early introduction of egg prevent egg allergy in infants? A population based study. J Allergy Clin Immunol. 2010;126:807-813. https://doi.org/10.1016/j. jaci.2010.07.028

16. Bellach J, Schwarz V, Ahrens B, Trendelenburg V, Aksünger Ö, Kalb B, et al. Randomized placebo-controlled trial of hen's egg consumption for primary prevention in infants. J Allergy Clin Immunol. 2017;139(5):1591-1599. https://doi.org/10.1016/j. jaci.2016.06.045

17. Boyano-Martinez T, Garcia-Ara C, Diaz-Pena JM, MartinEsteban M. Prediction of tolerance on the basis of quantification of egg white specific IgE antibodies in children with egg allergy. J Allergy Clin Immunol. 2002;110:304-309. https://doi.org/10.1067/mai.2002.126081

18. Sicherer SH, Sampson HA. Food allergy. J Allergy Clin Immunol. 2006;117:S470-S475. https://doi.org/10.1016/j.jaci.2005.05.048

19. Sicherer SH, Allen K, Lack G, Taylor SL, Donovan SM, Oria M. Critical issues in food allergy: a national academies consensus report. Pediatrics. 2017;140(2):e20170194. https://doi. org/10.1542/peds.2017-0194

20. Meyer R. Nutritional disorders resulting from food allergy in children. Pediatr Allergy Immunol. 2018;29(7):689-704. https://doi.org/10.1111/pai.12960

21. Dupont C, Chouraqui JP, Linglart A, Bocquet A, Darmaun D, Feillet $\mathrm{F}$, et al. Nutritional management of cow's milk allergy in children: an update. Arch Pediatr. 2018;25(3):236-243. https://doi.org/10.1016/j.arcped.2018.01.007

22. Meyer R, Godwin H, Dziubak R, Panepinto JA, Foong RZM, Bryon $M$, et al. The impact on quality of life on families of children on an elimination diet for non-immunoglobulin $\mathrm{E}$ mediated gastrointestinal food allergies. World Allergy Organ J. 2017;10(1):8. https://doi.org/10.1186/s40413-016-0139-7 